\title{
UMA ANÁLISE DA MUNICIPALIZAÇÃODO ENSINO NO ESTADO DE SÃO PAULO
}

\author{
ANGELA MARIA MARTINS \\ Fundação Carlos Chagas \\ Programa de Pós-Graduação da Universidade Católica de Santos \\ amartins@fcc.org.br
}

\begin{abstract}
RESUMO
O texto analisa alguns resultados de pesquisa mais ampla que avaliou a implementação do convênio estado-municípios no que diz respeito aos serviços educacionais do ensino fundamental no Estado de São Paulo. Tomando como cenário o contexto político-adminitrativo e dados de transferência da administração de escolas estaduais para o nível local, o estudo original buscou investigar as características do processo gestor de dois municípios, escolhidos com base nos índices de cobertura do ensino fundamental, nas características de suas políticas de formação continuada e no seu perfil de arrecadação fiscal. Discutem-se, neste artigo, apenas as características do processo de transferência de escolas, alunos e professores para as redes municipais de ensino.

POLITICAS PÚBLICAS - GESTÃO - MUNICIPALIZAÇÃO DO ENSINO - ENSINO FUNDAMENTAL
\end{abstract}

\section{ABSTRACT}

ANANALYSIS OF THEELEMENTARY SCHOOLSASSIGNMENTFROMTHESTATETO THE MUNICIPALITIES IN THESTATE OFSÃOPAULO. The text discusses some results of a more comprehensive research aimed to assess the implementation of a state-municipalities agreement to provide elementary education in the State of São Paulo. Considering the political-administrative context, as well as data on schools assignments from state to local schools, the original study searched to identify the characteristics of the management process of two municipalities, chosen on the basis of their elementary schooling coverage, theirpolicies on teacher's continued education and the cities taxpayer profile. This article focuses specially on the characteristics of the two Municipal Education Departments management process, based on interviews with the Departments' main authorities, members of the Municipal Board of Education and school principals and vice - principals.

PUBLICPOLICIES-MANAGEMENT - TEACHINGMUNICIPALITIES-ELEMENTARYSCHOOL 
Parte de pesquisa mais ampla, este texto analisa aspectos da implementação do convênio estado-município referente à manutenção do ensino fundamental. No estudo original, foram discutidas as diretrizes da política estadual paulista no que tange à municipalização dos serviços educacionais, com base na análise do conjunto legal-normativo e nos documentos oficiais que a orientam, a partir de 1996. Nessa etapa, foram coletados, ainda, dados relativos a: prefeitos; partidos; regiões administrativas; regiões de governo; diretorias de ensino; número de escolas; professores e alunos municipalizados entre 1996 e 200 I ; matrículas municipais; escolas municipais; valores repassados e recebidos do governo federal, por municípios no Estado de São Paulo, entre 1998 e 2000, via Fundo de Manutenção e Desenvolvimento do Ensino Fundamental e Valorização do Magistério - Fundef'.

Tomando como cenário o contexto político-adminitrativo e os dados de transferência, o estudo original buscou investigar as características do processo gestor de dois municípios cujas administrações foram escolhidas com base nos índices de cobertura do ensino fundamental, nas características de suas políticas de formação continuada e no seu perfil de arrecadação fiscal ${ }^{2}$. Procurou-se analisar as principais variáveis intervenientes da transferência para as Secretarias Municipais de Educação, com base em entrevistas realizadas com as equipes envolvidas, na tentativa de verificar se esse processo dificultou ou facilitou a gestão do ensino municipal: o conhecimento das questões técnicas e políticas; as possibilidades de aprendizagem no percurso; a compreensão e/ou resistência às mudanças geradas no desenho institucional; atuação dos órgãos colegiados: o Conselho Municipal de Educação e o Conselho de Acompanhamento Fiscal e sua relação com o poder executivo municipal.

1. A pesquisa intitulada O processo de municipalização no Estado de São Paulo: mudanças institucionais e atores escolares, coordenada por Angela Maria Martins, recebeu financiamento da Fundação de Amparo a Pesquisa do Estado de São Paulo - Fapesp. No estudo original, os dados foram sistematizados e analisados por José Roberto Rus Perez, do Programa de Pós-Graduação da Faculdade de Educação da Unicamp, pesquisador convidado da Fundação Carlos Chagas, a quem agradecemos a participação. Eles estão organizados e disponíveis em banco de dados na biblioteca da Fundação Carlos Chagas.

2. Os dois municípios são grandes, com população entre 500 mil e 800 mil habitantes. Possuíam, até 1997, uma rede de atendimento municipal de educação infantil, um quadro de professores e diretores com salário acima do dos profissionais da rede estadual, escolas muito bem equipadas e consistentes políticas de formação continuada. 
Embora o estudo não tenha analisado os aspectos tributários que envolvem a operacionalização do convênio, pois isso exigiria outro tipo de abordagem cuja ênfase não reside propriamente na teoria política, a questão dos recursos sempre veio à tona durante a realização das entrevistas no âmbito das equipes centrais das duas Secretarias Municipais de Educação. Não constituiu, porém, objeto de análise (Martins, Perez, 2002).

É preciso, ainda, que algumas considerações sejam feitas sobre o conceito de mudança institucional utilizado no estudo. As implicações na utilização dos termos inovação, reforma e mudança são muitas e não há um consenso na literatura da área acerca do conceito que melhor explicite as características de cada processo. De modo geral, o discurso recente que embasa as diretrizes do que se convencionou denominar reformas dos sistemas de ensino não faz distinção entre os termos, considerando-os, de certa forma, semelhantes ${ }^{3}$. A despeito dessa heterogeneidade, adotou-se como referência básica o conceito de mudança institucional relacionado a mecanismos não estabilizadores ${ }^{4}$ que ocorrem por força de novos rumos imprimidos na gestão do Estado, e que implicam a adoção de reformas estruturais que reconfiguram o exercício e as relações de poder.

Nesse sentido, partiu-se do pressuposto de que a implementação de políticas alinhadas à ampliação do exercício da democracia, ou de políticas orientadas para as mudanças exigidas pela economia de mercado, tem sido condicionada, num caso ou noutro, por relações de macropoder que criam demandas e reorientam a gestão das políticas setoriais, promovendo mudanças institucionais significativas. O sentido de reforma educacional, neste caso, está diretamente relacionado às mudanças efetivadas na estrutura do próprio sistema de ensino as quais promovem, concomitantemente, inovações na organização político-pedagógica das escolas. Pode-se afirmar, com certa tranqüilidade, que a implementação do

3. Ver, a esse respeito, a discussão realizada por Afonso (1998) sobre as diferentes posturas assumidas por diversos autores que analisam o tema.

4. Ver, sobre o conceito de mudança em sociologia: Lipset (1977, p. I9 I). O autor destaca a importância da análise funcionalista, bem como as contribuições do estruturalismo para o conceito de mudança social, salientando que, embora preocupados com os níveis de estabilidade dos sistemas sociais, os autores que se alinham a essas correntes de pensamento admitem que todos esses sistemas são constituídos por mecanismos estabilizadores e não estabilizadores. Exatamente por isso, é possível administrar os conflitos surgidos em processos de mudança como decorrência natural de mecanismos antagônicos que tendem a se acomodar de um modo ou de outro. 
convênio estado-município em curso representa uma expressiva reorganização político-administrativa do sistema público estadual paulista, com conseqüências no âmbito pedagógico sem precedentes na história da educação no Estado de São Paulo.

\section{A POLIITICA E SUA GESTÃO: PROCESSOS DECISÓRIOS E PODER LOCAL}

A discussão sobre democracia na literatura política invariavelmente vem acompanhada de ponderações acerca das reais possibilidades de compartilhamento do poder e da representação dos cidadãos. $O$ tema é analisado, de um lado, por teóricos defensores da formalidade imposta pelas regras do jogo democrático, ou em outras palavras, pela defesa incondicional dos procedimentos formais de delegação da representação, com base em eleições que consagram a convivência democrática. De outro, encontram-se os defensores da conquista do aumento de participação daqueles que se acham sub-representados, mesmo que essa ampliação ainda represente uma defesa dos canais legitimados pela formalidade dos procedimentos democráticos. Ao longo do século XX, no campo da teoria política a discussão sobre as transformações inevitáveis e inerentes às sociedades democráticas e aos seus mecanismos de funcionamento, oscila entre a defesa dos procedimentos formais de participação social e política dos indivíduos e a constatação da complexidade da distribuição do poder nessas sociedades, isto é, sobre a necessidade de ampliação dos canais de representação.

Para Bobbio (2000), entre os nobres ideais - cujos princípios legais e normativos fundamentam a democracia desde o liberalismo - e a realidade concreta, um processo de transformações sociais, históricas e econômicas mudou seus mecanismos de funcionamento, acrescentando-lhes propriedades diferentes. Assim, a concepção individualista que lhe deu origem - contrariando a concepção orgânica de sociedade prevalecente nas sociedades antigas e medievais, e partindo do princípio do indivíduo soberano que, de acordo com outros indivíduos soberanos, criaria a sociedade política em um regime sem intermediários -, confrontou-se com a realidade social de organizações, grupos, associações, sindicatos, interesses partidários, de uma sociedade, enfim, burocratizada.

Nas últimas décadas, a preocupação central acha-se dividida entre a idéia de manter a democracia nos moldes liberais, baseada sobretudo na representação exclusivamente via eleições, ou a de ampliar seu próprio conceito, inspirando-se nas idéias socialistas para a defesa da ampliação da participação e da representação 
daqueles segmentos sub-representados. De qualquer modo, a adoção de procedimentos formais como via legítima para que a democracia represente interesses heterogêneos generalizou-se ao longo do século $X X$ e continua sendo a forma que dá vida aos regimes democráticos, embora outros teóricos sublinhem que tais procedimentos estão longe de ser sua substância.

De acordo com Santos (2002), a tensão entre capitalismo e democracia, sobretudo nos países centrais, visando priorizar a acumulação do capital e controlar a redistribuição social na tentativa de evitar o que se denominou sobrecarga democrática, explodiu após os anos de 1980. A pressão criada por segmentos sociais que nunca tiveram acesso às políticas de proteção - acrescida da pressão formulada por outros segmentos inseridos nessas políticas -, criou demandas sobre as democracias formais que buscaram respondê-las com diferentes estratégias de governo, contaminando os países periféricos ou semiperiféricos. As estratégias adotadas para reorientar a capacidade de atendimento das democracias ocidentais às demandas crescentes variam de acordo com as características históricas, políticas, econômicas e culturais dos países envolvidos, no entanto, de modo geral, consolidou-se a idéia de uma democracia capaz de controlar a governabilidade, em detrimento da idéia de uma democracia capaz de inserir a pluralidade contida nos segmentos excluídos, sem deixar de atender aos que já estavam assistidos.

As concepções hegemônicas de democracia que vigoraram ao longo da segunda metade do século $X X$ procuraram responder basicamente a três questões: à complexidade da relação entre procedimento e forma; ao papel desempenhado pela burocracia na vida das sociedades democráticas modernas; e, finalmente, à complexidade de que se reveste a representação nas democracias de larga escala. Porém, essa discussão não soluciona o problema crucial de saber se as eleições esgotam os procedimentos de autorização dos cidadãos e se a representação esgota o problema da diferença. A questão da inevitabilidade da burocracia nas sociedades modernas é outro problema que parece não solucionado pelas democracias formais (Santos, 2002).

Ao longo do século $X X$, o Estado de bem-estar social fez com que as questões de ordem burocrática adquirissem conotação positiva na análise de boa parte do pensamento político, com exceção das críticas formuladas por Foucault. Segundo Santos,

... a concepção tradicional de gestão burocrática (nos moldes weberianos) advoga uma solução homogênea para cada problema, a cada nível de gestão 
administrativa, no interior de uma jurisdição administrativa. No entanto, os problemas administrativos exigem cada vez mais soluções plurais nos quais a coordenação de grupos distintos e soluções diferentes ocorrem no interior de uma mesma jurisdição. (2002, p.48)

No rastro desse debate, insere-se a defesa do desmonte do aparelho burocrático que dá vida às sociedades democráticas ocidentais: se os problemas são heterogêneos, sua solução deve ser buscada em diferentes procedimentos e níveis administrativos da gestão da coisa pública, em contraposição às políticas centralizadas e burocratizadas implementadas até meados do século XX. Finalmente, a questão da autorização para que os cidadãos se achem representados também não está solucionada nas democracias formais.

Em escala ampliada, o exercício da democracia buscou soluções na facilidade encontrada pela representação formal. Porém, encontrou dificuldades no que diz respeito à prestação de contas e à representação das múltiplas identidades, fazendo com que os choques de interesses étnicos, de opção sexual, religiosos, raciais etc. fossem inevitáveis. Na contracorrente das concepções hegemônicas de modo geral defensoras dos procedimentos formais para autorização da representação dos cidadãos como únicos canais legítimos de prática democrática -, houve uma revalorização dos preceitos democráticos, baseados, no entanto, em novos mecanismos de participação social e política.

Uma solução apontada após os anos de 1980 para que a democracia liberal se viabilize como regime hegemônico é a ampliação da participação local dos cidadãos. Supõe-se que a democracia exercida em escala menor - nas localidades - facilite a superação dos problemas gerados pelos diferentes níveis da burocracia, bem como pela complexa questão da representação. Nas cidades, por exemplo, as condições para o desenvolvimento de experiências alternativas e o exercício de práticas democráticas seriam maiores, estariam delimitados territorialmente, se beneficiariam da proximidade do poder e seriam baseados na criatividade dos atores locais. Essa idéia encontra respaldo nas teorias contrahegemônicas de democracia que também defendem uma convivência e uma complementariedade entre níveis de escala dentro do regime democrático (Santos, 2002).

Resta uma pergunta: até que ponto ou de que maneira os novos desenhos institucionais surgidos de formas experimentais de exercício democrático podem mudar substancialmente o modelo hegemônico de democracia? Em outras palavras, de que forma a dinâmica instaurada em razão da descentralização de proces- 
sos decisórios, tais como este aqui analisado, pode configurar um novo desenho institucional para a prática da democracia em pequena escala, permitindo: aperfeiçoamento na gestão das políticas; participação efetiva dos atores escolares nas decisões coletivas; encaminhamento de soluções mais efetivas e eficazes para os graves problemas configurados pela burocratização da implementação de políticas? Ou os novos desenhos correm o risco de ser apenas a reconfiguração de velhas formas de gestão das políticas públicas?

\section{PROCESSO DE MUNICIPALIZAÇÃO NO ESTADO DE SÃO PAULO}

Após o fim do Regime Militar e a instauração de um processo de democratização política, a redistribuição das receitas públicas para dotar as subunidades federadas de maior autonomia financeira, ao que tudo indica, ainda está longe de resolver de forma satisfatória a redefinição do desenho das políticas setoriais no Brasil, embora tenha iniciado um percurso de mudanças fundamentais para que o modelo de gestão de Estado centralizado seja superado. De modo geral, a indefinição de competências, a dispersão de esforços e recursos, as dificuldades para se responsabilizar as diferentes esferas executivas pela inexistência ou inadequação da prestação de serviços têm sido as características do processo descentralizador no Brasil. De qualquer forma, a descentralização tem ocorrido baseada na redistribuição das receitas de um lado, e, de outro, fundamentada em novos arranjos político-institucionais, com a redistribuição de competências entre as diferentes esferas de governo. Como medida última, o processo descentralizador tem transferido, gradativamente, funções do setor público para o setor privado lucrativo ou não lucrativo, com base na instauração de parcerias e convênios.

A agenda política implementada a partir de meados dos anos 1980 na educação paulista - centrada no discurso da descentralização e da autonomia da escola como um dos principais instrumentos para instaurar uma gestão democrática após anos de regime militar - derrapou até meados dos anos de 1990, no modelo de gestão de Estado intrinsecamente ligado a mecanismos centralizadores. A ruptura com esse modelo teve início a partir da metade dos anos de 1990, com a vitória do ideário que defendia um projeto de modernização administrativa, constituindo-se um campo de tensão no planejamento educacional a partir da instauração de processos descentralizadores. Dentre as principais medidas que operacionalizaram esse processo de mudanças institucionais no Estado de São Paulo, está a transferência de escolas, professores e alunos de $1^{\text {as }}$ a $4^{\text {as }}$ 
séries aos municípios ${ }^{5}$. Historicamente, a cobertura do ensino fundamental tem sido feita pelo setor público, com especial destaque para a maciça participação da Secretaria Estadual da Educação, responsável por 79\% das matrículas nesse nível de ensino, por exemplo, em 1995. Com a redefinição de competências entre as esferas de governo a partir de 1996, intensificada nos anos seguintes, os municípios passaram a assumir a responsabilidade pelas matrículas de $1^{\mathrm{a}}$ a $4^{\mathrm{a}}$ série, saltando de $12 \%$ para $44 \%$ a sua participação no conjunto da oferta no período de 1996 a 200 I, enquanto a rede estadual caía de 77\% para 44\%.

\section{GRÁFICO I}

DISTRIBUIÇÃO DAS MATRÍCULAS DE ENSINO FUNDAMENTAL ( $\left(^{\mathrm{a}}-4^{\mathrm{a}}\right.$ SÉRIE) SEGUNDO DEPENDÊNCIA ADMINISTRATIVA SÃO PAULO, 1996 - 200।

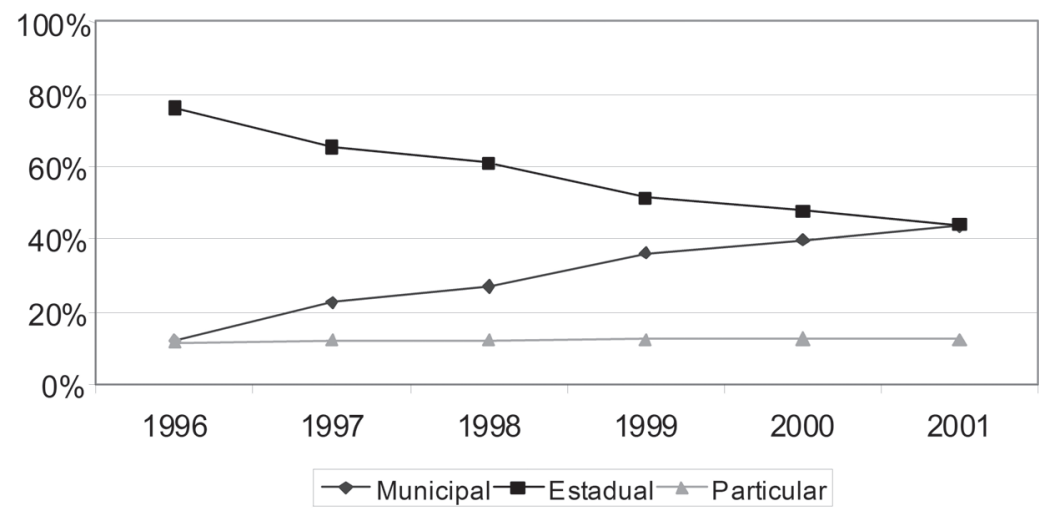

Fonte: Centro de Informações Educacionais - CIE/Secretaria de Estado da Educação de São Paulo SEESP.

5. O Decreto n.40.673/96, posteriormente alterado pelo Decreto n.40.889/96, instituiu o Programa de Ação de Parceria Educacional Estado-Município para atendimento ao ensino fundamental, consolidando o processo de municipalização, iniciado em 1989 , com o Decreto n.30.375/89. O instrumento administrativo criado para viabilizar o programa foi um Termo de Convênio, do qual faziam parte um Plano de Trabalho do município com objetivos e metas, um Plano de Aplicação dos Recursos e um Cronograma de Desembolso Financeiro. $\mathrm{Na}$ assinatura dos dois primeiros eventos de municipalização, apenas 46 municípios apresentaram todas as condições legais e financeiras para aderir à parceria. Os professores, diretores e coordenadores pedagógicos foram cedidos por cinco anos de vigência dos convênios, embora sua situação funcional não se alterasse: continuariam sendo funcionários do estado, sem perda das vantagens trabalhistas, e o estado permanecia responsável por seus salários e aposentadorias. Mensalmente os municípios deveriam reembolsar ao estado apenas o montante da folha de pagamento desses profissionais. 
processo de municipalização teve início em 1996 e foi marcado pela adesão de um pequeno número de municípios (6,7\%). Nesse mesmo ano, o Fundef foi discutido e finalmente aprovado pelo Congresso em dezembro. No ano seguinte, ocorreu a maior proporção de municipalizações, período em que um terço dos municípios assinaram o convênio com a Secretaria Estadual, antecipando-se, dessa forma, à implantação do Fundef. Coincidentemente, 1997 foi o primeiro ano das novas gestões eleitas. Em 1998, ano em que finalmente foi implantado o Fundef, deu-se um refluxo e apenas 43 municípios aderiram à municipalização. Vale lembrar que nesse ano houve eleições para governador e presidente da República. Em 1999, o processo tomou fôlego novamente, incorporando mais $18 \%$ dos municípios. Finalmente, nos dois últimos anos abrangidos por esta análise, ocorreu um declínio do número de adesões que atingiram no máximo 6\% dos municípios.

Ao final desse processo, em 200 I , vislumbrava-se a seguinte situação, conforme os dados da tabela 2: 67,9\% dos municípios haviam aderido ao processo de municipalização e passaram a oferecer ensino fundamental; $12,7 \%$ deles já possuíam uma rede própria e mantiveram-na e 19,4\%, continuaram sem uma rede municipal.

TABELA I

PORCENTAGEM DE MUNICÍPIOS, SEGUNDO O ANO DE REPASSE

DAS ESCOLAS ESTADUAIS PARA A SUA ADMINISTRAÇÃO

SÃO PAULO, 1996 - 200I

\begin{tabular}{c|c|c|c|c|c|c|c}
\hline \multirow{2}{*}{ Ano } & \multicolumn{7}{|c}{ Municipalização } \\
\cline { 2 - 8 } & 1996 & 1997 & 1998 & 1999 & 2000 & 200 I & TOTAL \\
\hline$\%(\mathrm{~N}=645)$ & 6,7 & 30,4 & 6,7 & 18,1 & 1,9 & 4,2 & 67,9 \\
\hline
\end{tabular}

TABELA 2

PORCENTAGEM DE MUNICÍPIOS QUANTO À MANUTENÇÃO

DAS ESCOLAS DE ENSINO FUNDAMENTAL

SÃO PAULO, 200 I

\begin{tabular}{l|c}
\hline COM ESCOLAS RECEBIDAS DA REDE ESTADUAL & 67,9 \\
\hline COM REDE MUNICIPAL PRÓPRIA & 12,7 \\
\hline SEM REDE ESCOLAR & 19,4 \\
\hline TOTAL DE 645 MUNICÍPIOS & 100,0 \\
\hline
\end{tabular}

Fonte: CIE/SEESP. 
A análise desse processo de municipalização segundo o porte do município ${ }^{6}$ aponta para alguns dados muito relevantes quanto ao momento de adesão e à intensidade. No primeiro ano de municipalização, foram os municípios grandes que mais aderiram. Os municípios de porte médio passaram a municipalizar com mais intensidade no segundo ano, em 1997. Os municípios pequenos entraram nesse processo mais intensamente em 1997 e 1999, mas continuaram municipalizando ainda nos três anos seguintes (Gráf. 2). Ao final desse processo, em $200 \mathrm{I}$, ainda existiam 32\% dos municípios pequenos que não possuíam rede municipal de ensino fundamental, entre os municípios médios, havia $10 \%$ e entre os grandes apenas $2 \%$ estavam nessa situação. Também havia um conjunto de municípios que não aderiram ao processo de municipalização porque já possuíam rede própria de ensino fundamental. Nesse caso, encontravam-se $28 \%$ dos municípios grandes, $15 \%$ dos médios e $8 \%$ dos pequenos.

GRÁFICO 2
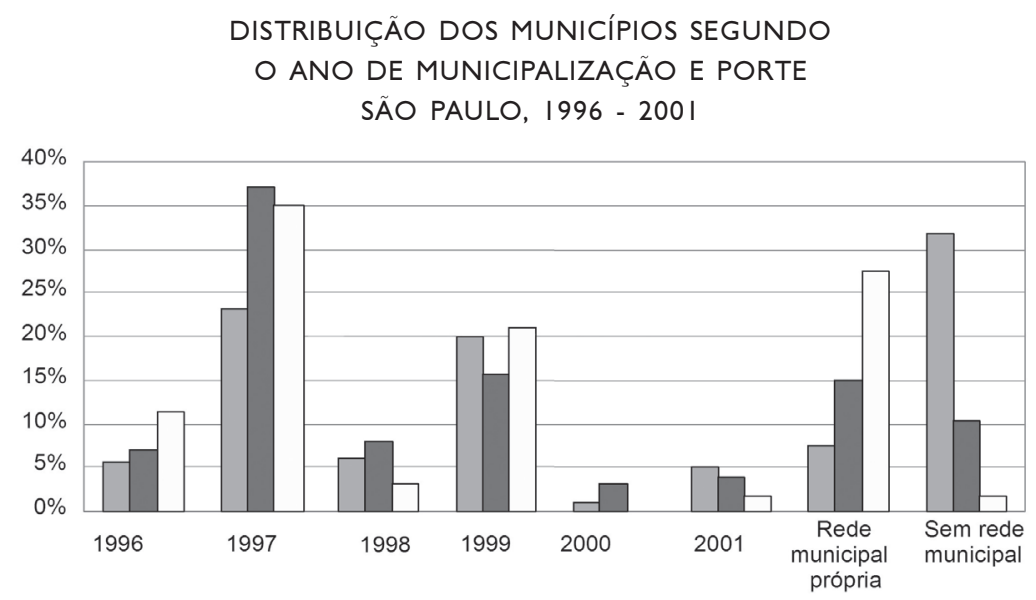

Pequeno porte $\square$ Médio porte $\square$ Grande porte

Nota: Centro de Informações Educacionais - CIE/Secretaria de Estado da Educação de São Paulo SEESP; Fundação Instituto Brasileiro de Geografia e Estatística do Rio de Janeiro - FIBGE (disponível em: http//:www.ibge.gov.br; acessado ao longo de 200 I e 2002).

6. Os municípios do Estado de São Paulo foram classificados segundo o número de habitantes: porte pequeno (até 10 mil habitantes), médio (de 10 mil a 100 mil habitantes) e grande (mais de 100 mil). Dos 645 municípios, 45\% eram pequenos, 45\%, médios e 10\%, grandes. 
desenho institucional que se formou na política educacional paulista em decorrência do convênio que transferiu professores, alunos, prédios escolares e funcionários da esfera estadual para os municípios é fragmentado e forma um mosaico de interesses díspares, o que nos permite afirmar que a sacralizada cultura burocrático-administrativa consolidada nos anos de 1970 começa a sofrer fissuras, para o bem e para o mal. Considerando-se as enormes desigualdades regionais no tamanho, formas de atendimento, desempenho e capacidade fiscal dos municípios paulistas, configura-se uma engenharia operacional de transição na qual os novos papéis institucionais têm sido testados de todas as formas, pois pode-se afirmar, com certa tranquilidade, que cada município é um caso. A retirada de cena da esfera executiva federal, substituída, em parte, pelas novas prerrogativas dadas aos estados e municípios para que estes passem a assumir novas competências de gestão, não constitui apenas um problema técnico, mas esbarra exatamente na cultura política sacralizada em torno de negociações nem sempre pontuais.

O campo de tensão constituído nesse processo apresenta elementos do projeto de modernização encetado desde fins dos anos de 1970 e elementos tradicionais que a eles se mesclam, potencializando, na rede de escolas, comportamentos de resistências, omissões, dissimulações e/ou simplesmente de adesões às orientações oficiais por meio de cumprimento ritual das ordens emanadas. Acrescente-se que a cultura institucional - o sistema de crenças, valores e de interação dos atores entre si e entre estes e a própria organização -, ao ser instada a se modificar, metaforiza parte do ritual normativo, incorporando o velho no novo desenho que se forma como estratégia de sobrevivência. Da mesma forma, o clima organizacional - técnicas e procedimentos; política de recursos humanos; metas, regulamentos e estatutos; comportamento encorajado dentro da instituição; atividades de caráter integrador etc. -, também sofre um processo de aprendizagem em contextos de mudança, conforme se observou na pesquisa de campo.

O cenário político recente, em que predomina a defesa da localidade como espaço apropriado para exercício da democracia em pequena escala, parece adequar-se à necessidade de se instaurar em novas formas de gestão da rede de escolas, tendo em vista a comprovada ineficiência e ineficácia dos grandes sistemas de ensino para oferecer um ensino de qualidade e de responder com agilidade aos problemas suscitados das mais diferentes ordens, em regiões completamente diferentes entre si. Nessa perspectiva, os problemas heterogêneos que permeiam as redes de escolas, aparentemente, encontram alguma solução mais 
imediata nos diferentes procedimentos e níveis administrativos da gestão municipal, pois a proximidade com o poder executivo, ao que tudo indica, além de ampliar a participação dos profissionais do ensino, também perturba mais diretamente o centro desse poder, no caso, as Secretarias Municipais de Educação e/ou o gabinete do prefeito.

Porém, em contextos de mudança institucional nos quais ocorrem negociação de transferência de responsabilidades e/ou de compartilhamento de poder, pode-se constituir um paradoxo. A necessidade de forjar novas formas de desempenho das políticas educacionais exige que as instituições envolvidas em sua implementação adquiram um corpo de informações e de conhecimentos burocrático-administrativos para assumir suas novas funções, o que, sem dúvida, gera um período de tensão política e de vácuo no conjunto normativo-legal, pois sua racionalidade não responde mais às necessidades do cotidiano. Isto é, entre o que este conjunto propugna para que a gestão da política educacional funcione em outro paradigma, e sua efetiva operacionalização, configura-se um período de instabilidade institucional que imprime rumos inesperados às suas diretrizes, na tentativa de romper a cultura fortemente enraizada em seus órgãos gestores e nas próprias unidades escolares. É nesse vácuo que os professores, diretores e coordenadores pedagógicos têm sido chamados a desempenhar suas funções, enfrentando as inovações propostas pelas Secretarias Municipais de Educação, estas próprias protagonistas estreantes em seus novos papéis institucionais, pois acabaram de assumi-los. Temos, portanto, uma dupla aprendizagem: da própria esfera executiva municipal que está aprendendo a desempenhar suas novas funções e dos atores escolares, demandados a serem criativos, colaboradores, a aceitarem as mudanças propostas e a compreenderem a situação de indefinição profissional a que estão submetidos.

A conduta da Secretaria Municipal de Educação (que será designada por A) foi no sentido de negociar a transferência de alunos e professores, construindo, nesse processo, o que se convencionou denominar "condomínios", pois as escolas municipalizadas, em alguns casos, funcionavam dentro das escolas estaduais onde, durante um período de tempo, conviveram no mesmo espaço físico professores, diretores e coordenadores pedagógicos estaduais e municipais. Em outros casos, o estado construiu o prédio e a prefeitura assumiu sua gestão. Essa situação gerou, em uma das escolas analisadas, uma relação de colaboração efetiva, em que as duas diretoras trabalharam em conjunto encaminhando e resolvendo as situações de ordem administrativa e pedagógica. 
Em outra cidade (designada aqui por B), o processo de transferência se deu através do "repasse" de escolas estaduais para a prefeitura, com base em uma discussão sobre municipalização que teve início em março de 1997, envolvendo toda a rede de ensino na cidade. O principal argumento nas discussões realizadas sublinhava que o Fundef - elemento indutor desse processo -, não deixava margem de manobra para o executivo municipal. Na realidade, a esfera executiva estadual constitui o centro gestor centralizado do Fundef, uma vez que detém a maior parte do atendimento, competindo a esta esfera repartir os recursos, o que the possibilita reforçar os mecanismos daquilo que se denomina "ultrapresidencialismo estadual"7. O município, até 1998, não assumia o ensino de la a $4^{a}$ série, resumindo-se a gerenciar uma rede de pré-escolas. No final de 1998, elaborou-se o estatuto do professor municipal, e em 1999 estruturou-se o Departamento de Educação. A reconhecida "falta de experiência política, burocrática e administrativa" para gerenciar um volume maior de recursos financeiros e a expansão das equipes centrais gerou um processo tenso de mudança institucional.

De qualquer forma, apesar de o processo de transferência de escolas, professores, funcionários e alunos se constituir em objeto de polêmica e estar permeado de contradições, houve consenso na opinião dos entrevistados, ao defenderem a mudança física e simbólica do locus de negociação entre os atores escolares e o poder executivo, embora reconheçam os riscos dessa proximidade. Essa aproximação parece contemplar a reivindicação pela ampliação da participação dos atores escolares e da comunidade, pois os canais de comunicação são encurtados e os conflitos gerados nesse processo são negociados diretamente com os gestores dos sistemas municipais.

O desenvolvimento de estratégias e mecanismos governamentais de indução para que os municípios adiram aos programas de descentralização do governo federal - e o Fundef é um dos principais deles -, não exclui o complexo processo de negociação entre as esferas federal, estadual e municipal, visto que os arranjos político-partidários originam as mais diferentes barganhas. Nesse sentido, a proximidade proporcionada pela delimitação do espaço territorial entre instâncias de atuação e níveis administrativos parece contemplar a reivindicação pelo alargamento das bases democráticas de funcionamento da rede de escolas, de um lado. De outro, os mesmos profissionais entrevistados sublinham que essa proximida-

7. Ver a discussão feita por Abrucio (1998) sobre essa questão. 
de é potencialmente perigosa, pois os conflitos de poder, nesse sentido, podem ser utilizados em sentido contrário àquele que alimentaria a dinamização do exercício democrático.

Como em todo processo de mudança institucional, corre-se o risco de configurar-se, no desenho da política educacional estadual paulista, um vácuo legal-normativo, pois todas as prescrições do conjunto de orientações da Secretaria de Estado da Educação de São Paulo esbarram nas peculiaridades dos municípios envolvidos, permeadas por profundas diferenças na cobertura dos serviços educacionais. Tem ocorrido um aumento sem precedentes dos encargos administrativos, pedagógicos e financeiros para os municípios, considerando que nas Secretarias Municipais não existia, até então, uma cultura burocrático-administrativa e financeira, pois todo o conjunto normativo era de responsabilidade restrita da esfera estadual. Na implementação do convênio, esse arcabouço - que não é pequeno - está sendo assumido pela esfera municipal, com a otimização dos Conselhos Municipais de Educação e/ou com a estruturação de um sistema de supervisão da rede de escolas.

Mudar as bases de negociação não é tarefa simples nem constitui um simples mecanismo burocrático. As esferas executivas têm procurado responder às novas demandas postas para a gestão da política educacional, com diferentes estratégias de governo que variam de acordo com as características históricas, políticas, econômicas e culturais dos municípios envolvidos. Sem sombra de dúvida, a necessidade de ampliação da participação dos atores envolvidos em sua operacionalização é condição sine qua non para que os problemas heterogêneos encontrem soluções, também diferenciadas, localizadas na gestão municipal. Dessa forma, o redesenho institucional das próprias Secretarias Municipais de Educação - seus novos órgãos e fluxogramas - bem como os Conselhos Municipais, configuram novas formas de gestão da política educacional.

Porém, a democracia, sua prática e seus canais de expressão não se resumem a um problema de escala. Ao que tudo indica, não é de todo improvável que ocorram reversões de algumas das expectativas, pois a burocratização dos canais de participação dos atores é inevitável. Portanto, o risco de se introduzirem outras e novas formas de negociação dos diferentes interesses é grande, considerandose que, fundamentalmente, esses processos em sociedades democráticas ocorrem em torno de grupos corporativos, estejam eles situados em quaisquer espaços nos quais a democracia possa ser exercida.

Algumas das principais questões que compõem a tensão configurada por esse jeito de fazer política, herança de um passado que se manifesta com inten- 
sidade no presente, não encontrarão solução imediata, pois a possibilidade de mudança na cultura institucional ainda não passa disto, uma possibilidade. Dentre os principais entraves ressaltam-se: a manipulação de informações por parte de segmentos que representam diferentes interesses locais; alguma indiferença e/ou desprezo em relação aos critérios estabelecidos pelas novas formas de administrar; a negociação de influências e níveis de participação nas decisões de impacto da esfera executiva, como: quem levará vantagem (entenda-se qual grupo) se tal medida for implementada? Sem dúvida, a reorganização dos conselhos locais, fundamentada em normas legais, diferenciadas das que prevaleceram até o presente momento, que constitui um processo de negociação cujas bases ainda sofrem de males hereditários, pode mudar substancialmente o modelo de gerenciamento da política educacional.

É necessário, contudo, olhar para esse processo compreendendo que ainda levará muito tempo para que a possibilidade de ampliação de participação dos atores escolares nos órgãos deliberativos locais seja de fato o resultado de amadurecimento da democracia participativa, e não mais um mecanismo de camuflagem na defesa de interesses pouco transparentes. Questões como o legado da cultura política local; a existência ou ausência de quadros capacitados tecnicamente para assumir a gestão de maiores recursos financeiros; a ampliação sem precedentes dos recursos humanos envolvidos; as diferenças nos níveis de participação dos cidadãos, formam um caldo político-institucional nesse período de transição. De um lado, esse caldo pode perturbar a estabilidade momentânea da gestão da rede de ensino. De outro lado, essa situação poderá gestar novas formas de relacionamento entre as esferas executivas se a aprendizagem gerada no processo conseguir dinamizar os canais de expressão locais, o que demonstraria maturidade política dos atores envolvidos.

Observou-se, também, que há uma disputa entre os profissionais que permaneceram nos quadros da administração estadual e aqueles que foram municipalizados. No cerne dessa disputa, está não apenas a apropriação do espaço físico e dos recursos das escolas municipais - muito mais bem equipadas em ambas as cidades -, sobretudo, o status adquirido por estes últimos quadros, tendo em vista que a diferença nas condições de trabalho oferecidas pelos municípios analisados são muito melhores. Embora a sensação de insegurança e de provisoriedade da situação trabalhista tenha diminuído à medida que os executivos municipais têm aperfeiçoado sua aprendizagem institucional, estruturado departamentos, organizado fluxogramas e treinado equipes técnicas para administrar maiores recursos financeiros e humanos, a sensação de não saber a quem obedecer ainda é bastan- 
te forte entre os profissionais e tem fundamento no próprio vácuo constituído nesse processo de transição. As dúvidas pairam sobre questões até então comuns: faltas abonadas, férias, décimo terceiro salário, formação em serviço.

As relações entre as Diretorias de Ensino Regional e as Secretarias Municipais de Educação também estão baseadas na racionalização do atendimento das matrículas, e tendo sido contornado o problema da demanda. De fato, até 1998, as redes municipais de ensino organizavam a matrícula de seus alunos independentemente da rede estadual. Essa falta de sincronia acarretou, muitas vezes, a superlotação de uma rede em detrimento da outra, comprometendo a otimização dos equipamentos públicos. Além disso, como as matrículas eram feitas na segunda quinzena de novembro - com o início das aulas em fevereiro -, as inesperadas demandas de vagas em determinados locais não podiam ser atendidas porque não havia tempo suficiente para novas contruções e/ou ampliação da escolas. A antecipação do cadastro feito em conjunto por ambas as esferas executivas, processo mediado pela União Nacional dos Dirigentes Municipais de Educação - Undime -, facilitou e otimizou o atendimento da demanda.

Porém, os mesmos problemas de reconcentração de poder local também são apontados pelos entrevistados. $\bigcirc$ enxugamento das antigas Delegacias de Ensino e sua reconfiguração local em cidades-pólo que atendem um número grande de escolas foi apontado como um entrave na agilidade, democratização e acesso dos profissionais da rede de escolas às informações e capacitações ministradas. Dessa forma, o novo desenho institucional evidencia que o processo de descentralização em curso não constitui simplesmente uma etapa subseqüente da descentralização financeira e fiscal, sem que sejam consideradas as peculiaridades que envolvem o complexo processo de negociação entre as esferas de governo. Nesse sentido, é inevitável que as administrações locais realizem uma leitura política sobre os possíveis ganhos e perdas resultantes do fato de assumirem, ou não, os compromissos de gestão da rede de escolas.

Em suma, o atendimento municipalizado aproxima mais os profissionais da educação, os alunos e seus pais do centro de decisão, facilitando constituir a pauta de reivindicações e localizando mais facilmente os conflitos entre estes e os gestores do sistema municipal. Porém, o processo tem sido permeado de problemas que se parecem eternizar no ensino público, pois a expansão repentina das redes municipais começou a provocar, ao que tudo indica, um rol de intervenientes, evidenciando que a tensão entre a expansão da cobertura dos serviços educacionais e a manutenção da sua qualidade é realmente difícil de ser resolvida. 
De uma parte, a mudança do locus de negociação - da esfera estadual para a esfera municipal - atingiu as reivindicações e/ou expectativas dos profissionais, acentuando ou normatizando de outra maneira os conflitos entre os pares e entre estes e o novo centro do poder: a Secretaria Municipal de Educação. De outra parte, contribuiu para que os profissionais realizassem uma releitura das mudanças institucionais, possibilitando a construção de uma aprendizagem mais do que pedagógica, política, pois se encontram, atualmente, na contingência de negociar em bases diferenciadas daquelas praticadas até então, possibilitadas pela proximidade do centro de poder. Porém, a emergência e consolidação de formas mais plausíveis de gestão descentralizada da escola pública dependerão do grau de maturidade política das instâncias e dos atores envolvidos nesse processo que será tanto maior quanto maiores forem as chances de se exercitar a democracia como prática e não como conceito.

\section{POSSÍVEIS CONCLUSÕES}

Na história da política educacional paulista mais recente, modificou-se radicalmente a natureza das relações entre a esfera executiva estadual e os municípios, porém, numa conjuntura, nem sempre favorável para que a efetiva descentralização seja bem-sucedida. Como demonstram os dados, o convênio atinge municípios de pequeno, médio e grande porte com capacidade fiscal, administrativa, perfil político-partidário e cobertura do ensino fundamental totalmente diferentes entre si, tendo construído, ao longo de sua história, mecanismos de participação da população local também diferenciados. A engenharia operacional em curso, ao desconsiderar as peculiaridades culturais, demográficas e socioeconômicas dos municípios paulistas, desenhou um mosaico fragmentado, originando não apenas um processo de municipalização, mas vários.

De um lado, pode-se dizer que, finalmente, o discurso prevalecente ao longo dos anos 1980 que enfatizava a necessidade de se desmontar o aparato burocrático ineficiente e centralizado da educação paulista foi atendido. Ninguém discorda que o exercício democrático exige atualmente uma revisão dos mecanismos de representação nas democracias de larga escala e que, no rastro desse debate, se insere a discussão sobre a necessidade de ampliação da participação local dos atores envolvidos na operacionalização das políticas sociais. De fato, de acordo com esse princípio político, o processo de municipalização em curso parece facilitar a superação dos problemas colocados pelos diferentes níveis da burocracia, bem como o desenvolvimento de experiências alternativas, delimita- 
das territorialmente e beneficiadas pela proximidade do poder. Esta dinâmica pode aperfeiçoar a complementariedade necessária entre os diferentes níveis de escala dentro do regime democrático. Dessa forma, há que se estabelecer processos transparentes de negociação com os municípios, considerando-se o porte, o perfil de arrecadação, sua inserção na economia regional e as características político-administrativas que permeiam o atendimento do ensino fundamental, tais como os índices de cobertura e peculiaridades de suas redes de escolas.

De outro lado, no entanto, os limites e a complexidade dessa engenharia institucional não podem colocar em risco os mecanismos estabilizadores da própria gestão do sistema e este processo não pode ser construído, permanentemente, na base da negociação nem sempre favorável para o poder local.

\section{REFERÊNCIAS BIBLIOGRÁFICAS}

ABRUCIO, F. L. O Ultrapresidencialismo estadual. In: ANDRADE, R. de C. (org.). Processo de governo no município e no estado. São Paulo: Edusp, Fapesp, 1998. p.87- 1 I7.

AFONSO, J. A. Políticas educativas e avaliação educacional. Portugal: Universidade do Minho, 1998.

BOBBIO, N. O Futuro da democracia. São Paulo: Paz e Terra, 2000.

LIPSET, S. M. Estrutura social e mudança social. In: BLAU, P. M. Introdução ao estudo da estrutura social, Rio de Janeiro: Zahar, 1977. p. 190-233.

MARTINS, A. M.; PEREZ, J. R. R. O Processo de municipalização no Estado de São Paulo: mudanças institucionais e atores escolares. São Paulo: Fundação Carlos Chagas, Fapesp, 2002. (Relatório final)

SANTOS, B. de S. (org.). Democratizar a democracia. Rio de Janeiro: Civilização Brasileira, 2002.

SÃO PAULO (Estado). Secretaria da Educação. Decreto n. 40.673, de 16 de janeiro de 1996. Institui o Programa de Ação de Parceria Educacional Estado/Município, para atendimento ao ensino fundamental. São Paulo: SEE, 1996. v. 41.

. A Municipalização do ensino fundamental: o sucesso e o processo. São

Paulo, 2002.

Recebido em: agosto 2003

Aprovado para publicação em: agosto 2003 